\section{Contribuição à mudança curricular na graduação da Faculdade de Medicina de Botucatu}

\section{Contributions to curriculum changes at Botucatu Medical School}

Eliana Goldfarb Cyrino 1

Agueda Beatriz Pires Rizzato 2

${ }_{1}$ Departamento de Saúde Pública. Faculdade de Medicina de Botucatu. Universidade Estadual Paulista. Rubião Junior, s/n. Botucatu, SP, Brasil. CEP: 18.618-970 E-mail:

ecyrino@fmb.unesp.br

2 Departamento de Pediatria. Faculdade de Medicina de Botucatu. Universidade Estadual Paulista, Botucatu, SP, Brasil

\begin{abstract}
This paper describes the innovations in the discipline of Pediatric Semiology and in a group of disciplines called Public Health III. Two cases were chosen: Public Health III (Administration, Social Sciences, Epidemiology, Ethics and Nutrition in Public Health) and Pediatric Semiology. Qualitative methods were used to describe and evaluate the cases. Public Health covered: Problems in Public Health, Nutrition and Planning in Health. The teaching model was centered on the inquiry of situations routinely experienced in Health Centers and other Health Services. Pediatric Semiology focused on full assistance to children. The teaching model adopted was Problem Based Learning and practical teaching of Pediatric Semiology in different scenarios, mainly in the outpatient department. The main goal was to design and utilize strategies offering a student-centered approach allowing for more independence to build and increase knowledge. As for Pediatrics, the model adopted was Comprehensive Medicine focused on child assistance. As for Public Health the focus was Community Medicine considering the reality captured by the work developed at SUS and primary care centers. This indicated the feasibility of changes in teaching and the possibility of innovating teaching in Medical Schools. Key words Education, medical, Problem-Based Learning, Pediatrics, Public Health
\end{abstract}

Resumo Descreve-se a inovação pedagógica de dois casos na graduação médica: uma matéria denominada Saúde Coletiva III, com (Administração, Ciências Sociais, Epidemiologia, Ética e Nutrição em Saúde Publica) e a disciplina de Semiologia Pediátrica. Para descrição e avaliação dos casos, utilizaramse métodos qualitativos. A Saúde Coletiva III foi organizada por núcleos temáticos: Problemas em Saúde Publica; Nutrição em Saúde Publica; Planejamento em Saúde. O modelo de ensino centrou-se na problematização de situações vivenciadas na prática da Saúde Publica, trabalhando-se em centros, serviços e organizações de saúde. A Semiologia Pediátrica privilegiou a atenção integral à saúde da criança. O modelo de ensino centrou-se na aprendizagem baseada em problemas e no aprendizado prático da semiologia pediátrica em diferentes cenários, enfatizando-se o ensino ambulatorial. Privilegiou-se o trabalho em pequenos grupos, com a orientação docente. A principal missão voltou-se à utilização de estratégias que valorizassem o ensino centrado no estudante e sua capacidade de construir conhecimento com autonomia. No caso da Pediatria, avançou-se rumo a Medicina Integral, com enfoque amplo do modelo de atenção à criança. A Saúde Coletiva aproximou-se da Medicina Comunitária problematizando situações concretas no SUS e na atenção primária. O estudo mostra a possibilidade de inovação no ensino, e podendo contribuir para a mudança institucional.

Palavras-chave Educação médica, Aprendizagem Baseada em Problemas, Pediatria, Saúde Pública 


\section{Contribuição à mudança curricular na graduação da Faculdade de Medicina de Botucatu: estudo de caso}

As instituições de ensino superior têm sido estimuladas a transformarem-se na direção de um ensino que valorize a eqüidade e a qualidade da assistência e a eficiência e relevância do trabalho em saúde. No caso específico da educação médica, a mudança significa formar médicos com habilidades adequadas às exigências da carreira profissional, a serem exercidas com responsabilidade e curiosidade científica, e que lhes permita recuperar a dimensão essencial do cuidado: a relação entre humanos.

Desde o início do século XX, o ensino de Medicina experimentou diversas propostas de reforma, das quais destacam-se as que tiveram maior influência na América Latina e no Brasil: a reforma Flexner, os movimentos da Medicina Integral e Preventiva e da Medicina Comunitária.1,2 A primeira reforma foi decorrente de estudo de Flexner, 3 publicado em 1910, que apresentava uma avaliação do padrão educacional de escolas médicas americanas e canadenses, frente à preocupação com desníveis de qualidade entre profissionais graduados em distintas escolas. Trata-se de uma reforma "cientificista", que propõe uma reconfiguração da prática educacional das escolas médicas "... essencialmente como uma capacitação técnica, cientificamente fundada ..." (Schraiber; 1989:109).2

A segunda reforma é representada pela Medicina Integral e sua expressão na educação médica: é a Medicina Preventiva. A Medicina Integral conforma-se no início de 1950, nos Estados Unidos, frente a necessidade de responder à crise de financiamento que se instalava, gerando enfrentamento entre a organização privada dos serviços médicos e o Estado. Objetivava aprimorar a medicina individual e superar seu caráter fragmentário, em função da crescente especialização da prática, mediante a concepção globalizadora do objeto individual: o paciente como totalidade biopsicosocial. Tal proposição exigiria das escolas médicas formar um profissional que atuasse apreendendo globalmente a complexidade do paciente, inclusive atingindo a família. 2,4

A terceira proposta, conhecida como Medicina Comunitária, difundiu-se na América Latina no início de 1970 com o apoio de agências internacionais de saúde. Surgiu nos Estados Unidos, na década anterior, enquanto política social voltada para atender os grupos sociais de baixa renda, que se encontravam excluídos do acesso à assistência médica. A Medicina Comunitária ofereceu conceitos voltados a se repensar o cuidado médico intimamente ligado às necessidades da população. ${ }^{5}$ Desse modo, ao buscar compatibilizar a necessidade de extensão de serviços com o problema dos custos crescentes da assistência médica, reconhece como essencial uma simplificação tecnológica nas práticas de atenção à saúde, tendo por base evidências epidemiológicas que apontavam maior prevalência de doenças mais simples em populações. Para a Medicina Comunitária, a escola médica forma profissionais inadequados para resolver os problemas de saúde da comunidade, dado o crescente privilegiamento do conhecimento em campos cada vez mais segmentados. ${ }^{2}$

É interessante perceber que na década de 90 as linhas gerais do movimento da Medicina Comunitária continuaram presentes no arcabouço das propostas de reforma implementadas na América Latina. Nesse sentido, continua atual a leitura crítica que faz Schraiber 2 dos reflexos desse movimento na educação médica, ao afirmar que o "privilegiamento da qualificação especializada" é tomado como se fosse decorrência de determinados "padrões técnicos do ensino" e, assim, sua superação é reconhecida como possível instruindo-se novas "competências técnicas individuais".

A base do ensino médico, na atualidade, volta-se muito aos avanços das novas e cada vez mais diversificadas tecnologias de diagnóstico e tratamento de enfermidades. Inúmeras doenças que até pouco tempo eram fatais, hoje são consideradas e tratadas como doenças crônicas, aumentando a expectativa de vida por muitos anos. Esse sucesso na manutenção da vida, no entanto, não tem sido acompanhado do desenvolvimento da habilidade médica de ouvir, de cuidar, de compreender a vulnerabilidade dos pacientes diante do sofrimento e ao adoecer. ${ }^{6}$

Comparando-se o início do século XX, quando os médicos possuíam recursos limitados para tratar e curar seus pacientes, apoiando-se no saber e na experiência pessoal de cada médico, dedicando seu tempo para dar suporte, cuidado e conforto aos doentes de modo a desenvolver uma relação de confiança, a partir da década de 1960, com o desenvolvimento técnico-científico, surge um novo panorama, com uma maior divisão de trabalho médico. Consequentemente, com a mudança do modelo de atenção à saúde, o trabalho médico passou a se realizar de forma bastante fragmentada, impessoal e com valorização de habilidades técnicas em detrimento de uma relação médico-paciente mais humanizada. ${ }^{7}$ É paradoxal, neste sentido, que enquanto a confiança na medicina, como prática técnica, tenha se ampliado durante a segunda metade do século XX, a confiança nos médicos foi reduzindo-se, instalandose uma crise de confiança. 
Frente a todo o aparato da tecnologia médica, a Escola Médica tem preparado médicos "equipamento-dependentes". Esses médicos "... se desprovidos de senso crítico, poderão mais assegurar o consumo de bens e serviços, condicionados por interesses econômicos, do que atender às necessidades de saúde identificadas ... " (Magaldi; 1982: 8). ${ }^{8}$

A partir da década de 1990, novos modelos de ensino médico vêm sendo construídos em diversas escolas da América Latina, buscando-se uma reformulação do mesmo. Esses projetos propõem um ensino médico voltado para o desenvolvimento de atividades que tomam como objeto necessidades sociais de saúde, a busca de novos cenários para o ensino/aprendizado em saúde, como as unidades básicas de saúde, e a própria idéia de um ensino médico que articule os diferentes níveis de atenção à saúde, à integração dos serviços de saúde.

Almeida, 9 em estudo recente sobre as possibilidades de mudança da Educação Médica, apresenta, baseado em um estudo de Ferreira, 10 diferentes propostas de mudança na educação médica relativas a alterações nos processos, nas relações e nos conteúdos e afirma que essas iniciativas poderiam sinteticamente ocorrer em planos diferentes de profundidade das mudanças: o plano da inovação, o plano da reforma e o plano da transformação.

$\mathrm{Na}$ perspectiva de contribuir para a melhoria do ensino e da aprendizagem na universidade, a inovação pode ser reconhecida como possibilidade de ruptura com o paradigma dominante, com o desenvolvimento de formas alternativas de trabalhos que quebrem a estrutura tradicional.11 Muitas vezes na contra-mão do modelo dominante de ensino, e mesmo de uma visão de inovação tecnicista e alienante, o modelo de inovação que procura explorar novas alternativas que se abrem ao conflito e contradições, pode ser relevante marco para a construção de novas possibilidades no ensino médico.

O presente estudo investigou experiências inovadoras localizadas, que poderiam dar indícios de processos de rupturas e, portanto, contribuir para melhoria do processo educativo. É um estudo de caso, no qual as pesquisadoras acompanharam o planejamento e a execução da intervenção, analisando e avaliando o processo, tratando se assim de uma pesquisa-ação.

A virtude da pesquisa-ação está relacionada à possibilidade de produção de conhecimento sobre a inter-relação entre sujeitos e saberes envolvidos em uma prática social.

No estudo de caso sempre há uma escolha de um determinado foco, um determinado espaço, um grupo e esse será sempre um ato artificial, pois im- plica na fragmentação do todo onde está integrado. ${ }^{12}$ O investigador, embora considere a relação da parte a ser estudada com o todo, e dada a necessidade de controlar a investigação, delimita a matéria em estudo. Apesar de buscar um caso que constitua por si só uma unidade, a separação do todo sempre conduz a alguma forma de distorção, como conseqüência e limitação do próprio método. Para o observador, a parte escolhida para estudo é considerada como tendo uma identidade própria. 12

Os casos escolhidos para estudo foram uma disciplina e uma matéria composta por um conjunto de cinco disciplinas, oferecidos e ministrados ao terceiro ano da graduação médica da Faculdade de Medicina de Botucatu (FMB). Os casos foram reconhecidos como interessantes por suas singularidades, por terem ambos assumido na sua formulação pressupostos da reforma curricular da FMB ocorrida em 1996. Trata-se de experiências de inovações pedagógicas que utilizaram a aprendizagem por descoberta, sendo que na disciplina de Semiologia Pediátrica, a ênfase maior foi a utilização da Aprendizagem Baseada em Problemas (ABP) e novos cenários de ensino e na matéria Saúde Coletiva III, trabalhou-se com a ABP e a problematização de situações em diferentes serviços e níveis de atenção à saúde.

Os casos foram analisados a partir de um conjunto de dados. Como procedimento metodológico, para descrevê-los foram utilizados diário de classe, programas, planos de ensino, roteiros de aula de professores e para alunos, observações e anotações de reuniões de preparação de aula, textos e produções construídos no curso. Para avaliar a disciplina e a matéria, foi solicitado aos alunos, na forma de um questionário aberto, que fornecessem informações sobre os pontos positivos de cada caso estudado e sugestões para melhoria dos mesmos. Também lhes foi solicitado que escrevessem uma carta hipotética para um futuro estudante que realizaria o mesmo curso no ano seguinte, comentando os pontos relevantes.

A presente pesquisa foi aprovada pelo Comitê de Ética em Pesquisa da Faculdade de Medicina de Botucatu da Universidade Estadual Paulista (UNESP).

\section{A problematização e a aprendizagem baseada em problemas (ABP) como estratégias de modelos de ensino- aprendizado}

Em 1998 e 1999, no planejamento da matéria Saúde Coletiva e da disciplina de Semiologia Pediátrica na 
FMB, frente à insatisfação com a continuidade do currículo tradicional, buscaram-se rupturas a partir do desenvolvimento de duas metodologias problematizadoras: a problematização e a aprendizagem baseada em problemas.

Dentro das metodologias problematizadoras, a problematização e a aprendizagem baseada em problemas são duas propostas distintas que "... trabalham intencionalmente com problemas para o desenvolvimento dos processos de ensinar e aprender..." Apoiadas na aprendizagem por descoberta e significativa, ambas valorizam o "aprender a aprender" (Berbel; 1998: 141),13 utilizando uma seqüência de conteúdos organizados para facilitar a percepção do todo.

A partir do pioneirismo da Universidade de McMaster, no Canadá, no final dos anos 60, o modelo da ABP se expandiu para muitas escolas de Medicina em todo o mundo. Muitas das características da APB já estavam presentes em uma reforma curricular da Escola de Medicina da Universidade de Case Western Reserve, nos anos 50, que incorporou e integrou um conjunto de métodos e estratégias instrucionais em laboratório multidisciplinar. 14 A ABP é considerada uma das mais significativas inovações na educação médica nos últimos anos, surgindo como um movimento de reação aos currículos das escolas médicas sob a forte influência do modelo flexineriano de ensino, que privilegiava o modelo biomédico e o ensino centrado no hospital. Ela pode ser considerada como o eixo principal do aprendizado teórico de um currículo médico, objetivando o aprendizado de conteúdos cognitivos e a integração de disciplinas. Propõe-se a um trabalho criativo do professor que estará preocupado não só com "o que", mas, essencialmente, com "o como" o estudante aprende.

A ABP é adotada em diversas instituições e no Brasil duas escolas médicas destacam-se no desenvolvimento de currículos em ABP: A Faculdade de Medicina de Marília (FAMEMA) e a Faculdade de Medicina do Centro de Ciências da Saúde da Universidade de Londrina (UEL). Na FAMEMA desenvolve-se um programa de ensino/aprendizagem centrado no estudante, baseado em problemas e orientado à comunidade. $15 \mathrm{Na}$ UEL, a introdução da aprendizagem baseada em problemas buscou romper com a dicotomia entre os ciclos básico e clínico e permitir ao estudante assumir uma postura mais ativa na construção do seu conhecimento. 16

A "problematização" tem, nos estudos de Freire, 17 uma formulação que enfatiza a percepção de que os problemas, os temas a serem estudados partem de um cenário real, em que educação e inves- tigação temática são momentos de um mesmo processo. Internacionalmente, na área da Saúde, metodologias problematizadoras surgiram na década de 1980, pela necessidade de buscar currículos orientados para problemas que melhor definissem como os estudantes aprendem e que habilidades cognitivas e afetivas estão sendo adquiridas. Uma proposta foi implementada na Enfermagem, na Universidade do Havaí, nomeada como "ensino baseado na investigação" (inquiry based learning), que inclui uma abordagem interdisciplinar de aprendizagem e solução de problemas, pensamento crítico e responsabilidade do aluno pela sua própria aprendizagem. (Feletti; 1993: 143).14

Para Berbel (1998: 141)13 a Metodologia da Problematização "... constitui-se uma verdadeira metodologia, entendida como um conjunto de métodos, técnicas, procedimentos ou atividades intencionalmente selecionados e organizados em cada etapa, de acordo com a natureza do problema em estudo e as condições gerais dos participantes." $\mathrm{O}$ professor, na educação problematizadora, buscará com os estudantes revisitar e construir, no âmbito do contexto trabalhado, interpretar a realidade voltando-se à criação de espaços contra-hegemônicos e contestatórios que possibilitem uma crítica, muitas vezes radical, à realidade estudada. 13

As duas propostas são, em seus núcleos teóricos constituintes, formulações distintas. A problematização tem como objetivo fundamental "... a mobilização do potencial social, político e ético dos alunos, que estudam cientificamente para agir politicamente, como cidadãos e profissionais em formação, como agentes sociais que participam da construção da história de seu tempo, mesmo que em pequena dimensão." (Berbel; 1998: 145).13 É, portanto, uma proposta metodológica que visa desvendar a realidade para transformá-la. Sua maior contribuição é a mudança de mentalidade, exigindo, dos atores envolvidos no processo educativo a reavaliação de seus papéis, re-significando coletivamente o processo de ensino-aprendizagem. A problematização insere-se numa concepção crítica de educação. A ABP, inspirada na Escola Nova, propõe-se a preparar cognitivamente os alunos para resolver problemas relativos a temas específicos do ensino da profissão. 18

Tanto a ABP como a problematização têm em comum uma pergunta focal (o que está acontecendo?) como padrão geral para se obter novas informações, análise e síntese do que foi aprendido. Mas o ponto de partida, os pressupostos e a estrutura de trabalho desenvolvida é bastante diferente. O problema é mais abrangente na problematização, sendo formulado a partir da observação dos estudantes 
frente a uma realidade, enquanto na $\mathrm{ABP}$ o problema é apresentado aos alunos pelo professor-tutor. $\mathrm{Na}$ problematização não há restrições quanto aos aspec- tos incluídos na formulação dos problemas. 14 (Figu-

ra 1)

Figura 1

Processos vivenciados na problematização e na aprendizagem baseada em problemas.

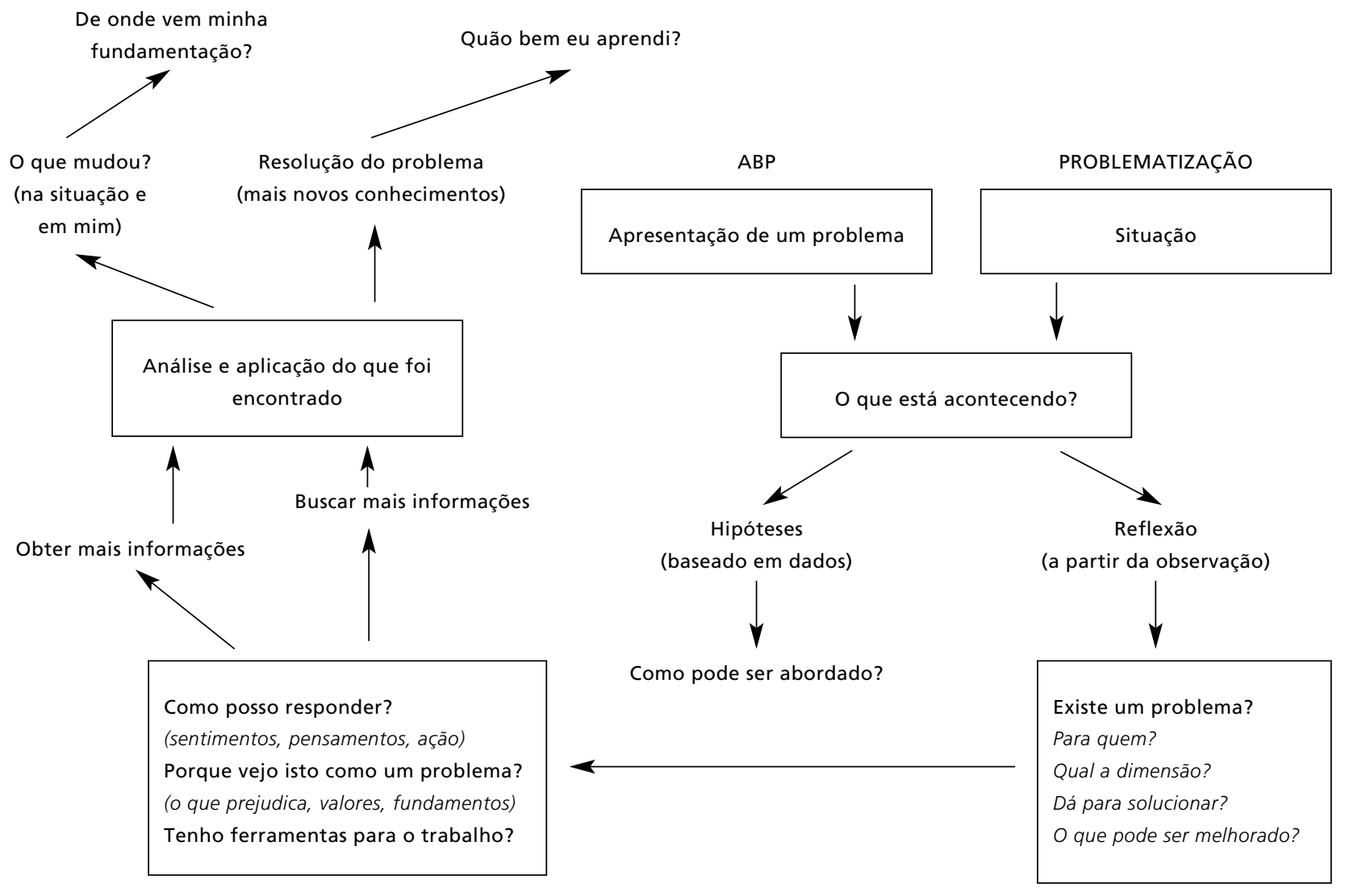

$A B P=$ Aprendizagem Baseada em Problemas

Fonte: Modificado de: Felleti G. The challenge of problem based learning. New York; 1991.14

\section{Os casos em estudo}

Em que pese os mais de 30 anos de difusão da Medicina Comunitária, que exerceu forte influência na proposta da Atenção Primária à Saúde, aprovada em Alma-Ata, 19 em 1978, é interessante perceber que no Brasil houve mudanças muito mais significativas na reorganização do sistema de saúde do que na maioria das escolas médicas brasileiras. Discutindo o compromisso social da Escola Médica, Magaldi8 relata que, na década de 1980, no Brasil, havia incipientes experiências de ensino médico em serviços públicos de saúde extra hospital-escola e que as mesmas não eram assumidas pela Escola Médica como um todo. A autora coloca que "... em uma posição de torre de marfim, a Escola Médica fica pairando acima do sistema de saúde, pouco ou nada colaborando no planejamento de saúde, regionalizado, (...). Esse encastelamento não seria uma forma de evitar que alunos e professores percebam, com mais realismo, as contradições sociais?" (Magaldi; 1982: 6). 8

No final dos anos 90, Campos, 20 em estudo so- 
bre o treinamento médico nos hospitais-escolas universitários e nos serviços do SUS (Sistema Único de Saúde) no Brasil, selecionou 14 escolas médicas públicas, observando uma pesada concentração do treinamento em hospitais (86\%) e, em contra-partida, $14 \%$ das escolas realizavam treinamento em serviços de atenção primária. Observou ainda, que esses hospitais-escolas tinham sua organização voltada ao modelo da especialização médica, com uma grande fragmentação do ato médico e do cuidado à saúde.

Pode-se dizer que na maioria das escolas médicas, no Brasil, o ensino aplicado é realizado, predominantemente, nos hospitais, em geral, bastante especializados, sejam eles universitários ou não. Mesmo naqueles casos em que ocorrem projetos docentes assistenciais, incluindo projetos de extensão com Centros de Saúde Escola ou parcerias com serviços estaduais e municipais de saúde, com estágios em Centros de Saúde, na grande maioria dos casos, trata-se de proposições geralmente isoladas e ligadas aos Departamentos de Medicina Preventiva, com alguma participação de outros departamentos, como os de Pediatria.

Existe um "fechamento" na Medicina à saúde pública, alunos e professores subestimam a necessidade de incorporação de seus saberes para o exercício de uma boa clínica ou da boa medicina. "A meta das faculdades deveria ser formar médicos com alta capacidade de resolver problemas de saúde." (Campos; 1999: 189).20 Isso incluiria uma revisão no ensino de Saúde Pública.

No caso da Pediatria pode-se dizer que se a característica da infância é a ilimitada energia, a curiosidade, a inquietude e a grande atividade corporal, intelectual e afetiva, portanto a prática pediátrica precisa "... desenvolver-se com estas mesmas características, exercendo e investigando as condutas assistenciais mais efetivas em promover vida e qualidade de saúde..." para a criança e o adolescente (Ceccin; 1997: 28).21 No entanto, em nossa sociedade, o cuidado da criança e a relação com o processo da doença infantil, ou mesmo com a criança enferma, na maior parte das vezes, é mediado pela normalização fisiopatológica e anátomoclínica ou suplementarmente, pela psicoterapêutica. Embora seja "... irrefutável a emergência de atenção às demandas de proteção biológica e comportamental da criança, esse conhecimento é apenas parte da relação de cuidados necessários à promoção da saúde." (Ceccin; 1997: 28). ${ }^{21}$ Porém, é nesse paradigma que está centrado o ensino de Pediatria na maioria das Escolas Médicas do Brasil. Orientar o ensino da pediatria, problematizando situações reais, nos diferentes cenários, estudando as histórias colhidas pelos estudantes, bem como os prontuários das crianças e as interações estudantes/mães, levantando questões sobre condições concretas de vida da população, pode desencadear um compromisso e uma ação mais responsável do futuro profissional.

A história desta instituição, na qual ocorreu o presente estudo de caso, espelha esse movimento geral vivenciado por um número grande de escolas médicas no Brasil. Em 1962, foi criada a Faculdade de Ciências Médicas e Biológicas de Botucatu (FCMBB) e em 1965, implantou-se o Curso de Aplicação em Medicina da FCMBB, numa época caracterizada por "... novas conquistas científicas, novos conceitos e reformulações universitárias. Justificável, portanto, que esforços tenham sido concentrados na atualização de métodos de ensino, na estruturação curricular renovada e na integração de ações dirigidas para concretizar a nova concepção de ensino médico no país." (Montelli, Magaldi; 1988: 57). 22

Algumas proposições desse período inicial perderam-se ao longo do tempo, porém outras se constituíram em alicerce para a construção do curso de medicina, sendo até hoje mantidas, como a proposição de uma maioria do corpo docente em tempo integral e dedicação exclusiva, maior tempo de dedicação à assistência e ao ensino, o ensino em pequenos grupos a partir do terceiro ano médico, participação do aluno com responsabilidade na assistência ao doente, a partir do quarto ano, e proximidade entre corpo docente e discente. 22 A Faculdade passou por vários períodos de subseqüentes reformas curriculares. Nota-se que, de 1968 a 1978, houve um acréscimo de $100 \%$ no número de disciplinas, principalmente no quarto e quinto ano, e em 1988 um novo aumento que resultou, principalmente, no surgimento de numerosas sub-especialidades.

Em 1989, iniciou-se um amplo debate sobre as possibilidades de realização de uma nova reforma curricular no curso médico. Esse debate culminou em uma reforma curricular aprovada em 1996 e implantada em 1997

Concomitante a esse processo, a FMB foi uma das Faculdades de Medicina do Brasil selecionadas para o desenvolvimento de um projeto denominado Projeto UNI (Uma Nova Iniciativa na formação de profissionais de saúde) financiado pela Fundação Kellogg. O projeto visava, entre outros objetivos, impulsionar o desenvolvimento de atividades inovadoras no ensino de profissões da saúde. 18

As principais mudanças dessa reforma referiramse a executar o projeto de integração disciplinar da 
seguinte forma: o ensino permanecia disciplinar, com momentos integradores, com a participação de todas as disciplinas do ano, com núcleos temáticos que abarcavam os conteúdos ministrados em cada disciplina (temas transversais). Outras disciplinas também buscaram renovar-se, como a Obstetrícia, integrando efetivamente a Universidade com o serviço de saúde municipal. Algumas disciplinas integraram-se como matérias, buscando trabalhar com a metodologia da problematização e disciplinas do internato integram-se em estágios únicos. Ocorreu ainda a criação de uma disciplina de introdução ao curso médico no início do primeiro ano e o ensino de semiologia passou a iniciar-se precocemente no segundo ano de graduação.

A partir de 2001, frente à implantação das novas Diretrizes Curriculares dos cursos de graduação em medicina, 23 do Ministério da Educação e ao Programa de Incentivo às Mudanças das Escolas Médicas no Brasil (PROMED) proposto e financiado pelo Ministério da Saúde, 24 o ensino médico da Faculdade de Medicina de Botucatu abriu-se a novo debate e novo projeto de mudança, buscando valorizar e integrar experiências bem sucedidas, que ocorreram ao longo dos 40 anos de história. Mais recentemente, a partir de 2003, o Departamento de Gestão da Educação na Saúde da Secretaria de Gestão do Trabalho e da Educação na Saúde do Ministério da Saúde introduziu novo incremento ao processo de mudança da FMB, por meio da apresentação de diretrizes de apoio à iniciativas inovadoras que se proponham a articular a rede de gestão e de serviços com as instituições formadoras de profissionais da área da saúde, buscando a construção de mudanças nas práticas de formação para a construção da integralidade da atenção à saúde da população e a educação permanente de trabalhadores para o Sistema Único de Saúde.

$\mathrm{Na}$ reforma curricular do FMB, ocorrida em 1997, assim como outros dois casos. A disciplina de Semiologia Pediátrica e a matéria de Saúde Coletiva III, compostas por um conjunto de disciplinas empenharam-se na possibilidade de inovações, que se mantém até o presente momento, reestruturando tanto a forma como o conteúdo, incluindo o processo de avaliação. O primeiro ano de desenvolvimento dessas experiências será descrito a seguir.

\section{Caso 1}

A disciplina de Semiologia Pediátrica, obrigatória no currículo do terceiro de graduação médica da FMB, foi ministrada a esse grupo em 2000, como uma disciplina semestral, com 103 alunos, divididos em duas turmas, com três períodos por semana.

O Departamento de Pediatria da FMB foi criado em 1968, e desde o início sempre valorizou o ensino de pediatria na graduação médica no espaço ambulatorial. Impulsionado pelo Projeto UNI, Botucatu, reformulou em 1993 o programa de ensino oferecido ao quarto ano médico da graduação, iniciando assim, o curso de Pediatria Comunitária. Em 1999, com a mudança curricular, esse Departamento passou a reorganizar especificamente a Semiologia Pediátrica, do terceiro ano médico, reconhecendo-se por alguns docentes, a necessidade de sua revisão. As mudanças referiam-se não só à proposição de centralizar o processo de ensino-aprendizagem em temas básicos da Pediatria, permitindo ao aluno entrar em contato com o recém-nascido, a criança e o adolescente em suas especificidades e compreender a relação mãe, criança e profissional, mas também permitir a entrada de novos cenários para as atividades teórico-práticas como Berçário, Centros de Saúde e Creches Municipais.

No ano de 2000, a disciplina foi assim estruturada: trabalhou-se com quatro problemas, na forma de $\mathrm{ABP}$, foram ministradas grandes conferências integradas aos temas discutidos nos problemas e enfatizou-se a prática pediátrica em diversos cenários. Buscou-se trabalhar uma visão integral da criança e foi oferecido ao estudante um primeiro contato com a Pediatria, dentro de uma visão bastante ampla do trabalho profissional. Em relação aos temas abordados, destacaram-se: Nutrição infantil, Imunização, Desenvolvimento e crescimento, Saúde mental, Adolescência e Propedêutica.

No ensino de propedêutica, todos os alunos deveriam estagiar em diferentes cenários para acompanhamento de consultas, realização de anamnese e exame físico. Assim estagiaram na Enfermaria Geral de Pediatria, na qual prevalecem crianças de diferentes idades com doenças de alta complexidade; no berçário, para o aluno ter contato com o recémnascido, a gestante, a puérpera, o conhecimento do alojamento conjunto, a sala de parto e o incentivo ao aleitamento materno; no ambulatório, que poderia ser no Hospital das Clínicas da FMB ou no Centro de Saúde Escola de Botucatu, no qual há possibilidade de contato com crianças sadias e com os problemas mais freqüentes da saúde da criança.

Em recente artigo sobre o ensino da semiologia pediátrica, Sucupira e Ferrer (2000: 108). 25 discutem que o mesmo "... não pode ser visto como algo abstrato e, portanto, universal, independente do contexto em que se realiza a consulta." Afirmam que deve se considerar na abordagem do paciente, e no ensino da semiologia pediátrica, as características do 
modelo de atenção à saúde e o acesso aos diferentes serviços por diferentes demandas.

Todos os professores envolvidos no desenvolvimento da ABP foram capacitados para participar das atividades e inclusive contribuíram na formulação e reformulação dos problemas.

Ao final do Curso de Semiologia Pediátrica foi distribuído um questionário aos alunos do curso e dos 103 alunos, 81 (79\%) responderam ao mesmo.

Alguns depoimentos dos alunos chamam a atenção no sentido de se poder perceber o quanto os mesmos se envolveram com o curso:

"O curso foi em si muito significativo e estimulante na minha formação. Assim, interessei-me muito pela pediatria"

ou

"A experiência de vivenciar as dificuldades quando se faz um exame físico em crianças que não colaboram foi um aprendizado" ou ainda

"Os assuntos são bem elaborados e encaixados no curso de acordo com nossos conhecimentos e as aulas práticas despertam interesse, assim como a boa vontade dos professores e a boa organização do curso".

Alguns estudantes criticaram a ABP, principalmente no que se referiu a freqüência da mesma no curso e também na indicação das referências, o que aparece na crítica de um aluno:

"... a freqüência a PBL é muito grande e os textos muito cansativos."

Pode-se perceber que no geral os alunos valorizaram as práticas nos distintos cenários, as diferenças entre os mesmos e a riqueza da experiência de poder vivenciar o contato com crianças em situações de saúde e doença também singulares. Perceberam inclusive características distintas dos cenários:

"... na enfermaria os diagnósticos são quase sempre os mesmos"

ou

"... no CSE pude observar como os médicos atendem e lidam com os pais e crianças"

Orientar o ensino da pediatria, problematizando situações reais, nos diferentes cenários, e estudando as histórias colhidas pelos estudantes bem como os prontuários das crianças e as interações estudantes/mães, levantando questões sobre condições concretas de vida da população, pode desencadear um compromisso e uma ação mais responsável do futuro profissional.

\section{Caso 2}

"Neste curso, caro colega, você acaba tendo um contato tão próximo com seus professores orientadores que fica até chato não participar das discussões. Os professores são bem interessados, mas às vezes exigem coisas que estão fora de sua disponibilidade, já que também temos milhares de outras matérias e atividades para conciliar. De qualquer maneira, agora vocês vão começar um bloco de Saúde Coletiva, bem diferente ... com trabalhos fora da FMB, ligados à Unidades de Saúde, Pronto Socorro, Secretaria Municipal de Saúde. Seu juízo crítico será valorizado e você não será apenas um aluno passivo e sim alguém que opinará e colocará seu ponto de vista em relação àquilo que vê. Boa Sorte. Espero que goste". (carta de um estudante para um colega hipotético que realizaria a matéria no ano seguinte)

A matéria Saúde Coletiva III, obrigatória no currículo do terceiro de graduação médica da FMB, foi ministrada (ao terceiro ano da graduação médica) a esse grupo em 1999, como um curso anual. Matricularam-se no curso 81 estudantes, com dois períodos por semana.

O Departamento de Saúde Pública (DSP) foi criado em 1968, e, desde a sua concepção, foi prioridade sua inserção na graduação médica, nas atividades de prestação de serviços de atenção básica na cidade e região de Botucatu e na elaboração e desenvolvimento de serviços. Em 1998, um grupo de docentes do DSP iniciou a elaboração de uma nova matéria a ser ministrada ao terceiro ano médico. A Saúde Coletiva III foi o resultado da junção de disciplinas que nesta configuração seriam oferecidas pela primeira vez em 1999. Foram elas: Epidemiologia, Nutrição em Saúde Pública, Ciências Sociais, Ética e Administração em Saúde Pública.

Os professores envolvidos na elaboração dessa nova matéria, com apoio técnico, reorientaram-na, tanto quanto ao aspecto metodológico quanto ao conteúdo e à forma de avaliação. Uma questão central foi a integração disciplinar realizada de diferentes formas e em diferentes momentos, com a apresentação de problemas transversais e com temas gerados pela problematização da realidade e propostos pelos estudantes.

Buscou-se elaborar uma matéria que facilitasse a compreensão do trabalho e das especificidades da Saúde Pública para o futuro médico, enfatizando-se questões como a importância do trabalho reflexivo, do ato de planejar, do trabalho em equipe, no qual a comunidade, também, tem um papel preponderante, da ética nas relações de trabalho do futuro médico 
com os outros profissionais de saúde, com a população atendida e com as instituições envolvidas no atendimento.

A possibilidade do uso de temáticas, que se constituíram em três módulos, foi um marco: "Problemas de Saúde, Nutrição em Saúde Pública e Planejamento". Participaram da execução professores que orientaram, cada um, diretamente, grupos de alunos. Propôs-se uma avaliação diária (auto-avaliação e avaliação do professor orientador) dos alunos e sistematicamente uma avaliação do desenvolvimento do curso. Por meio de diferentes metodologias, buscou-se problematizar a realidade, propondo-se que os grupos de alunos fossem estudando, interpretando e apresentando soluções às questões/vivências apresentadas.

Ao final da realização da matéria, um questionário aberto foi distribuído e dos 81 estudantes, $75(93 \%)$ responderam.

Analisando-se as respostas e cartas pode-se ver que algumas questões, destacadas pelos estudantes, foram intencionais na formulação do curso e percebidas por eles como tal:

"... você precisa não só das presenças nas aulas como também participar das aulas (e do começo ao (im)"

ou na colocação:

"... a oportunidade e a dificuldade de estar tão próximo dos professores".

O trabalho diário, de construção do grupo com orientação docente, foi uma prioridade. Outras questões destacadas como a dificuldade de se trabalhar em grupo, com colegas que não colaboravam, foi apontada por vários estudantes como um ponto que pode ter comprometido parte do trabalho coletivo. Os estudantes valorizaram de diferentes formas tanto o contato com a realidade dos serviços de atenção primária e com o Sistema Único de Saúde como a interação com profissionais de diversas organizações. Embora tenham apontado a dificuldade em compreender a Saúde Pública, seus conteúdos e a razão de estarem aprendendo uma série de assuntos, eles referiram que tudo isso poderia, no futuro, lhes ser útil para vida profissional:

"... Saúde Pública III é igual à camisinha, a gente nunca sabe quando vai usar ..."

Uma crítica dos estudantes referiu-se a dificuldade com o próprio conteúdo:

"... você vai começar o ano 2000 com o pé direito. Vai ser uma delícia acordar cedo para reuniões de grupos intermináveis ou para ler textos que nem quem escreveu entende."
Os alunos, de maneiras diversas, apontaram dificuldade em compreender o sentido do aprendizado do conteúdo da matéria. Com relação às metodologias utilizadas, as aulas teóricas são as mais criticadas:

"... aulas teóricas ... 90\% dos alunos não prestam atenção"

ou numa avaliação:

"O Departamento deveria entender que assuntos considerados essenciais para os docentes, nem sempre despertam a atenção e interesse dos alunos"

Outra crítica referia-se à diferença no trabalho de condução dos grupos pelos professores, mostrando que alguns aparentavam-se inseguros para discussão de alguns temas e isto foi claro na avaliação dos estudantes:

"As discussões sobre a organização dos serviços de saúde deveriam ser feitas pela professora A" ou

"A tutora era super interessada, mas não conseguia orientar o grupo sobre o tema, não era esclarecedora...".

Essa é uma questão essencial e que precisa ser esclarecida. Embora se soubesse antecipadamente o risco que se correria trabalhando com professores orientadores com níveis de conhecimento diferentes sobre as diversas temáticas, foi intencional o trabalho apoiar-se muito mais na possibilidade da criatividade e autonomia no desenvolvimento do trabalho pedagógico do que na homogeneização do conteúdo. Assumimos assim "... com todos os riscos e conseqüências, que a homogeneidade não existe quando se trata de trabalho com seres humanos" (Camargo; 1997: 68).26

No estudo do caso dos pacientes com Diabetes Mellitus, no qual a intervenção se deu no individual e no coletivo e se pode apresentar ao aluno o paciente, seu local de moradia, seu sofrimento e dificuldade para enfrentar uma doença crônica, muitas vezes sem sintomas claros, consultar o prontuário, conhecer a dieta real do paciente, o serviço de saúde que atende o doente, algumas questões foram de difícil apreensão na visão do aluno. Essa questão foi destacada no texto de um estudante:

"... prepare-se para ser bombardeado com conceitos fundamentais para sua formação médica, mas que irão chateá-lo um pouco por ser maçante e meio administrativo demais para pessoas interessadas no campo biológico humano e não no social ... Só que infelizmente estes não podem e nem devem ser separados". 


\section{As inovações dos dois casos frente ao ensino na FMB}

Pode-se reconhecer que a Faculdade de Medicina de Botucatu iniciou suas atividades em 1962, com um projeto inovador à época. Porém, muito embora possa ser reconhecido um enorme esforço ao longo desses anos objetivando, em diversas proposições de reforma do ensino, a formação do médico geral, o currículo foi se encaminhando rumo a um ensino com enfoque disciplinar, fragmentado, especializado e centrado em um hospital-escola, cada vez mais com características de um serviço de saúde de nível terciário. A vertente marcante do ensino médico tradicional na instituição não deixou de permitir, no entanto, experiências inovadoras significativas que marcaram a escola, envolvendo disciplinas, matérias ou cursos que, frente à demandas internas e externas, buscaram responder à formação de um médico geral crítico, criativo, com responsabilidade, ético e mais humano.

Para estudar as inovações descritas neste trabalho, foi preciso retomar a história da FMB, seus processos de reforma de ensino, suas possibilidades de avançar e sua rica história de ensino de graduação, sempre com um grupo de docentes envolvidos nos processos internos e externos em busca da melhoria da formação do médico. Se, muitas vezes, as propostas não se efetivaram enquanto prática, tal fato deveu-se à conjuntura do momento e, para isso, foi preciso rever a história para melhor compreender a situação institucional e relacioná-la à educação médica no país e no movimento mais amplo no contexto da Educação Médica no século XX. Nesse percurso, foi importante notar a influência de movimentos da Educação Médica norte-americana na FMB, desde seu período de criação e, inclusive, a presença de uma proposição de medicina científica, com elementos marcantes como a valorização da natureza biológica das doenças, a especialização, a prática experimental, a ênfase no procedimento curativo e a concentração do ensino no ambiente hospitalar.

A experiência recente de reforma de ensino na instituição demonstrou que não é possível se produzirem mudanças substanciais por decreto e muito menos se importarem modelos de ensino sem a devida discussão sobre a aplicabilidade dos mesmos à realidade específica da instituição.

Os dois casos aqui estudados são dois exemplos de inovações que ocorreram no espaço departamental; no caso da Semiologia Pediátrica, no limite de uma disciplina que se mobilizou no sentido de uma maior articulação entre a teoria e a prática. No caso da Saúde Coletiva III, a matéria organizou-se por núcleos temáticos, trabalhando-se os conteúdos articulados a questões práticas, problemas do cotidiano da saúde pública não localizados em uma disciplina especificamente, mas em várias que se uniram na construção de uma matéria única. A Pediatria avançou rumo a medicina integral. A Saúde Coletiva aproximou-se da medicina comunitária, proporcionou a problematização de situações concretas no SUS e na atenção primária.

Os resultados dos dois casos estudados mostraram que as experiências foram bem sucedidas. Um ponto forte dos dois refere-se ao uso de novas tecnologias educacionais que promovem no estudante mudança no seu agir. Assim, de alunos que ouvem, anotam, memorizam, os mesmos passam a se posicionar como sujeitos ativos, construtores de conhecimento e do aprendizado. Buscando conhecimentos de formas diferentes, dialogaram com diferentes atores e nesse processo os alunos sentiram-se bastante valorizados.

A sistematização das experiências e a apresentação dos problemas vivenciados, das dificuldades, e a complexidade dos processos podem contribuir para o aprimoramento dos casos e possivelmente mobilizar a instituição para um processo maior na caminhada da transformação de seu ensino.

Mudar, nessa perspectiva, significou poder aprender com novos contextos e compartilhar com os sujeitos o processo e sua avaliação, e isso foi implementado nos dois casos.

Buscou-se explicitar movimentos no ensino da Pediatria e da Saúde Pública que têm procurado um orientação pedagógica inovadora no ensino médico, no caminho da Medicina Integral e da Medicina Comunitária. Nesse processo foi possível perceber a ausência desse tipo de estudo e, principalmente, sentir que há um abismo entre o trabalho de pesquisa e o trabalho docente na graduação médica, que raramente se encontram ou se entrelaçam. Foi um trabalho em busca do registro da construção de uma prática profissional em educação médica, orientada por uma proposta criativa e tranformadora.

É preciso se ter clareza, porém, que, se o objetivo de uma escola médica for a reforma ou a transformação do seu ensino, não serão dois casos inovadores isolados que a promoverão, porque, de qualquer forma, no ensino médico o paradigma positivista ainda é muito forte e preponderante. Mas o germe da ruptura pode estar lançado. 


\section{Referências}

1. Arouca ASS. O dilema preventivista: contribuição para a compreensão e crítica da medicina preventiva [tese doutorado]. Campinas: Faculdade de Ciências Médicas da Universidade Estadual de Campinas; 1975.

2. Schraiber LB. Educação médica e capitalismo. São Paulo: Hucitec; 1989.

3. Flexner A Medical education in the United States and Canada. Bull Carnegie Fond Adv Teach (4), 1910.

4. Donnangelo MC. Saúde e sociedade. In: Donnangelo MC, Pereira L. Saúde e sociedade. 2. ed. São Paulo: Duas Cidades; 1979.

5. Cyrino APP. Organização tecnológica do trabalho na reforma das práticas e dos serviços de saúde: estudo de um serviço de atenção primária [dissertação mestrado]. São Paulo: Faculdade de Medicina da Universidade de São Paulo; 1993.

6. Puchalski CM. Reconnecting the science and art of medicine. Acad Med 2001; 76: 1124-5.

7. Schraiber LB, Mendes-Gonçalves R. Necessidades de saúde e atenção primária. In: Schraiber, LB, Nemes MIB, Mendes-Gonçalves RB. Saúde do adulto: programas e ações na unidade básica. São Paulo: Hucitec; 1996. p. 29-47.

8. Magaldi C. Compromisso social da escola médica. In: Anais do $20^{\circ}$ Congresso Brasileiro de Educação; 1982; Ribeiro Preto, São Paulo. Ribeirão Preto: ABEM; 1982. p. 1-12.

9. Almeida MJ. Educação médica e saúde: possibilidades de mudança. Londrina: UEL; 1999.

10. Ferreira JR. Análisis prospectivo de la educación médica Educ Med Salud 1986; 20: 26-42.

11. Cunha MI, Marsico HL, Borges FA, Tavares P. Inovações pedagógicas na formação inicial de professores. In: Fernandes CMB, Grillo M, organizador. Educação superior: travessias e atravessamentos. Canoas: ULBRA; 2001. p. 33-90.

12. Bogdan R, Biklen SK. Investigação qualitativa em educação. Portugal: Porto Ed; 1994.

13. Berbel N. A problematização e a aprendizagem baseada em problemas. Interface: Com Saúde Educ 1998; 2: 139-54.

14. Felleti G, organizador. The challenge of problem based learning. New York: St. Martin's; 1991.

15. Komatsu RS, Zanolli MB, Lima VV. Aprendizagem baseada em problemas. In: Marcondes E, Gonçalves E., organizadores. Educação médica. São Paulo: Sarvier; 1998. p. 223-37.
16. Gordon P. A new medicine curriculum in Londrina: the Dean's perspective on the change process project [master's dissertation]. Illinois: Department of Medical Education in the College of Medicine of the University of Illinois at Chicago; 2001.

17. Freire P. Pedagogia do oprimido. Rio de Janeiro: Paz e Terra; 1975.

18. Cyrino EG. Contribuições ao desenvolvimento curricular da Faculdade de Medicina de Botucatu: descrição e análise dos casos dos cursos de Pediatria e Saúde Coletiva como iniciativas de mudança pedagógica no terceiro ano médico [tese doutorado]. Botucatu: Faculdade de Medicina de Botucatu da Universidade Estadual Paulista; 2002.

19. Declaração de Alma Ata. In: Conferência Internacional sobre Cuidados Primários de Saúde; 1978 Set 6-12; AlmaAta, URSS. Disponível em: www.opas.org.br [13 jan 2004].

20. Campos GWS. Educação médica, hospitais universitários e o Sistema Único de Saúde. Cad Saúde Pública 1999; 15: 187-93.

21. Ceccin RB. Criança hospitalizada: a atenção integral como uma escuta à vida. In: Ceccin RB, Carvalho PRA, organizadores. Criança hospitalizada. Porto Alegre: Ed. UFRGS; 1997. p. 27-41.

22. Montelli AC, Magaldi C. Alguns aspectos do curso de graduação da Faculdade de Medicina de Botucatu: 1969-1988. São Paulo: FUNDUNESP; 1988.

23. Almeida M., organizador. Diretrizes curriculares nacionais para os cursos universitários da área de saúde. Londrina: Rede UNIDA; 2003.

24. Ministério da Saúde. Secretária de Políticas de Saúde. Coordenação Geral da Política de Recursos Humanos. Programa de Incentivos às Mudanças Curriculares para as Escolas Médicas (PROMED). Brasília: O Ministério; 2002.

25. Sucupira ACSL, Ferrer APS. Uma experiência de ensino de propedêutica pediátrica em ambulatório. Pediatria [São Paulo] 2000; 22: 105-12.

26. Camargo FM. A atualidade de Freire nos cursos de pedagogia. In: Freire AMA., organizador. A pedagogia da libertação em Paulo Freire. São Paulo: Ed. UNESP. 1999. p. 65-9.

Recebido em 7 de outubro de 2003

Versão final reapresentada em 14 de janeiro de 2004

Aprovado em 13 de fevereiro de 2004 